\title{
CROSS-NATIONAL MENTORING NGOS IN TRANSITION SOCIETIES: FIELD RESEARCH AND DEVELOPMENTS IN BULGARIA
}

\author{
Mariana Bogdanova \\ Cass Business School \\ Doctoral Programme, Management Faculty, London, UK \\ E-mail:m.bogdanova@city.ac.uk
}

Received 12 November 2007; accepted 28 March 2008

\begin{abstract}
Non-governmental organizations (NGOs) in societies undergoing socio-economic transition are widely regarded as central to building a civil society that encourages democracy. At the moment, the Bulgarian civil society depends greatly on foreign funding whilst NGOs are unable to empower their beneficiaries in decision-making. Given this reality, are cross-national NGO partnerships able to strengthen organisations? What kinds of support are on offer, what kinds of (inter) dependency relations occur and to what extent do NGOs model their management practices on their mentor and with what results?

This paper sets out to situate these questions in the context of a proposed theoretical construct, organizational mentoring, which occurs where national or local organisations have access to and support of well-established NGOs abroad. The model is constructed on the findings of a qualitative case study conducted in Bulgaria on the development of a Bulgarian NGO and its relationship with a UK NGO. This is preceded by a discussion on selected literature reflecting the meaning of transition, change in societal values and organizational practices in Eastern Europe, and the development of voluntary sector organizations in transforming countries. The theoretical model proposed here is relevant in providing a systematic discussion on organizational change towards a more enlightened engagement between civil society organizations in crossnational partnerships. Such discussion has implications for the development of hybrid forms of coexistence between Eastern and Western European partners reflected in their interdependent organizational practices.
\end{abstract}

Keywords: organizational mentoring, organizational change, transition, voluntary sector, NGO, civil society.

\section{Introduction}

In 2006 I attended a conference at the University of Bath in the UK titled Bringing the Voluntary Sector $I n$, which was running for a third year. Observing the transition of academic discourse at the conference over the three years, the issues surrounding the involvement of the voluntary sector in the economic and social development in Europe have clearly changed. At the outset in 2004, the dominating questions appearing in the summary of the conference revolved mainly around internal organizational issues, such as skills for the voluntary sector and capacity building. In the next two years the themes shifted to external organizational issues, including the relationship with stakeholders, borderlands between the voluntary sector, the state and business sectors, new complex forms of partnership, professionalisation, "communitization" and responsibilities of interorganizational engagement.

Each of these issues continues to need resolutions across the diversity of European settings, yet the agenda at the conference moved on visibly from micro to macro issues. It seems that in complex contexts, it is not when the issue is resolved that the next item on the list takes priority; rather each problem reaches its own tipping point and displaces a previous one. This raises the question when is it time to move on to the next thing? Similarly one can draw a parallel to the question of transition in societies undergoing major changes. At what point can it be considered that the country has moved on and its process of transition is over? Does this mean it has completed a "successful transition"? Has transition in Eastern Europe become a condition that lingers on for too long? Is it a construct used for self-referral for both those undergoing and those driving the transition?

Since transition takes place on a micro and macro scale, i.e. in organizations as well as in communities and society as a whole, as researchers of the organizations we need to consider to what extent the conceptual frameworks can be applied in studying the development of society as a whole. Lavigne (1999: 272) offers an important justification for this relationship - "as enterprise is often viewed as the core element of the transformation process, the contemporary developments of the theory of the firm are called upon". Therefore in 
looking at the societal side of transition rather than the economic one alone, the relevance of the enterprise as an organizational type can be projected onto that of the voluntary organization type. The voluntary sector, most prominently in the face of NGOs, is an agent of change in any country and a signifier of democratic change, especially in transitional settings. A case study of a Bulgarian NGO is presented here as a starting point for building a theoretical construct aiding the understanding of successful transition for an Eastern European country.

This paper sets out to situate the raised questions above in the context of a proposed theoretical construct, organizational mentoring, which emerged from a case study conducted in Bulgaria in 2004. A parallel is drawn between individual mentoring and the underlying value construction, the development of voluntary sector organizations in transition countries as an element of and agent of change, and the nature of transition itself on a societal level in a European context.

\section{The nature of transition}

It is commonly accepted that transition is a state of moving from underdevelopment to development as well as from planned to free market economy, though the connection between these two pairs is open to question. Transition states are distinct in their history, culture and, in terms of the place they take (or are given) in the larger context of their continent and globally. Their uniqueness is often overlooked by external decision-makers due to lack of time to look for differences when attempting to "make things work" in countries undergoing complex continuous change. The result of the migration to market economy is a mixed economy in which some of the former system elements are carried on and some pieces of the desired system are missing, for example the state administration and a well-functioning infrastructure (Lavigne 1999).

This mixed economy is hardly a combination of the best of the Western conventions and Eastern traditions, rather it is described by Lavigne as "mutant" and incoherent with the new or old systems where the missing pieces are substituted by "pathological fillers" like insiders' control, organized crime and corruption (ibid.). The "mutant" metaphor resembles, save the offputting undertone, that of the "hybrid" which has been revived in disciplines outside that of transition states as well (Brandsen et al. 2005). Hybrid-type organizations are sought by academics and practitioners outside East European transition settings as more competitive and representative varieties of organizations reflecting the complexity of partnerships today (like social enterprise). With this parallel in mind, mutant and hybrid metaphors are the two sides of the same coin in understanding the dynamics between Eastern and Western European counterparts in the transition process.

The study of hybridity in practice, however, is not as reassuring in terms of a collective knowledge creation process. Avramov's (2007) comparative work in the field of economics think-tanks in Eastern Europe reports that "Eastern economists consider themselves as simple theory-takers from the West" in that the motivation for Western messages and models to go East appears to be based on a re-exporting strategy. Hybridity is defined here not as a cross between cultures and intellectual traditions across West and East but rather a mix between competing imported models from the West. This distances the concept "hybrid" from the meaning set out at the dawn of the DIOSCURI project, hosting this research, which was initiated to discover forms of cultural coexistence between West and East, between new and old institutions, rules and practices (Kabakchieva 2006).

\section{The (un)importance of values and significant change}

When old ways of solving problems do not work the underlying assumptions and values are challenged. It is generally accepted that value change precedes behaviour change in incremental societal development (Chavdarova 2007). In Bulgaria however the change takes place everywhere simultaneously and at a fast pace. According to Chavdarova, what is observed in this case is a reconfirmation of well-established values as a coping mechanism to the resulting anomy, as well as responding to the emerging unfamiliar situations by behaviour change rather than by value change. Is behavioural change alone without the engagement on a deeper values level significant? This change can be considered as a kind of a "shallow adaptation", reported in research under the project DIOSCURI (ref). In studying rural development programmes in Bulgaria, Serbia and Croatia, Alexandrov (2007) observes that adaptive changes take place mostly at an individual level and hardly affect deeper levels of values and beliefs. Can such an adaptation which evades value change be argued to be adequate for instilling lasting change in the desired direction? Is a behavioural change alone sufficient to constitute a "successful" transition?

According to theory, value-based management discourse on organizational culture suggests that values 
need to be embedded in the organization guiding its behaviour and providing a basis for evaluating success (Deal et al. 1982; Alvesson 1991; Pettigrew 1990). It could be added that in turn, culture influences the values held which affect behaviour. Under this assumption of interrelatedness, some authors have argued that "actual culture" and "desired culture" need to be looked at comparatively as respectively representing cultural practices (behaviour) and cultural values (Alas and Tuulik 2007). The authors suggest that change in societal practices starts within and among organizations (ibid.: 44) yet others argue that change starts with the individual before institutions can change (Cassar, Bezzina 2005).

Overall, there seems to be a lack of clarity in theory as to where change starts and in practice, how to find the right place to plant yielding change. There is however undoubtedly both a push and a pull for change in transition countries which brings the discussion to another issue - is transition defined in terms of moving away from or moving to? Knowing what you are moving away from is knowing there is a need for transition and usually occurs from within the settings; it ends when you know what you are moving towards and when you reach that destination, which may be determined from outside the changing entity. Lavigne (1999) states in her conclusion that the transition countries in Europe know where they want to go and that we (East and West) are now all in the same boat (ibid.: 280).

Whilst academic research to date may be limited in explaining the interests embedded in Eastern and Western cultures, it nevertheless brings to light shifts in thinking regarded desired outcomes. The shifts in the debate away from "moving our way" towards "moving to a new direction", may be suggesting that transformation rather than transition is a more precise term in describing countries in Eastern Europe moving away from their socialist past (Burawoy 2001; Tvaronavičiene 2004). In this respect it is suggested that West-East relationships in certain settings may be better characterised as mentoring rather than directional or negotiated activity between "helper" and "helped".

The paper presents the research findings of an extended case study focusing on the Bulgarian Society for Protection of Birds (BSPB) and its relations with the UK -based but internationally well known Royal Society for Protection of Birds (RSPB) in support of this argument. As these organizations are a part of the voluntary sector, the following section introduces the sector and its characteristics in terms of an East-West co-creation.

\section{The voluntary sector in a transition context}

Much is written about voluntary sector organizations like NGOs (Non-governmental organizations) - their function, the importance of civil society, and the presence of Western countries in the affairs of the former Eastern bloc. It is hard to talk about transitional settings and NGO development there without encountering the major notions of the ideological West-East divide and political exchange outside NGO partnerships. Some commentators consider that NGOs are completely domesticated to the agendas of the dominant institutions and serve foreign interests. Others are more optimistic in believing that NGOs make a difference in their turbulent environments, yet others draw a distinction between compliant and independently thinking NGOs (Townsend et al. 2004). The existence of NGOs is heavily dependent on donor money and regulation from abroad yet they are accountable to national legal frameworks and need to demonstrate their representativeness to local constituencies. Most of the NGO literature focuses on the undesirable effects of external control through funding of large (international) NGOs or direct investment by setting up Western NGOs in the East (Maren 1997; Micklethwait, Wooldridge 2000; Crotty 2003).

State institutions possess a largely unfavourable reputation amongst its citizens. Their ineffectiveness is associated with reliance on bureaucratic mechanisms and paternalistic policies (Uphoff 1993). As their assisting hand, NGOs are seen, at least by external actors, as important in building a civil society and civil society as a sign of building democracy. NGOs are generally thought of as participatory, community oriented, democratic and a necessary component of a blossoming civil society in promoting communication, providing ground for activism and pluralism (Edwards and Hulme 1996; Mercer 2002). From within the state in question, however, NGOs may be generally distrusted or misunderstood, or at best, they are ignored as not being of first priority to a transforming country (Crotty 2003). NGOs are criticized for acting as project implementers rather than change-inducers, and generally fail to live up to their reputation of being a patron of civil society (Vivian 1994; Bebbington and Farrington 1993).

In Bulgaria, NGOs have been described as a "...refreshing alternative to the stifling bureaucracy of government", though not exactly a new alternative, as NGO activity is said to have historical traditions dating from the philanthropy of the 19th century and the Ottoman Empire (Pinnock 2002: 235). People living in the country however may doubt what local NGOs can 
achieve, and the importance of developing their civil society as a statement of democracy and change. The Bulgarian voluntary sector is under construction, highly underdeveloped, and a grey area of operation. Currently, NGOs are highly dependent financially, lack the power to influence business, lack the skills to involve communities in their work and are perceived as elitist by society due to their assumed position to be the voice of the people without their engagement (Andreeva et al. 2005). However, there are signs of a budding civil society though this is not always reflected in the formal structures of the voluntary sector (Popov 2007).

Experience has been bitter in trying to import the civil society concept and its models created in the West to a different socio-cultural environment in CEE countries (Wojnarowski and Jefferies 2000). This is largely due to lacking commonality among what the tools for change and desired outcomes are and what the operational concepts meant for both sides. The literature on transitional economies points to a divergent intellectual discussion in the East and West about what civil society means (Narozhna 2004). For example, while in the West the role of NGOs is a matter of defining and distinguishing between the different types in relation to institutional frameworks, in the East the context of NGOs is more practical and circulates around accountability and effectiveness in NGOs who strive to justify themselves to external funders and internal customers (ibid.).

Indigenous NGOs have to be able to demonstrate the terminology expected of them as experts and pioneers of change, which is a language embedded in the international arena of a Western rather than Eastern conceptual map. In her research on the impact of the NGO sector and "Roma/Gypsy" organisations on policy-making in Bulgaria, Pinnock (2002) argues that indigenous organisations have to speak with the jargon of democracy, integration and participation if their application is to receive attention from the European Community PHARE funding programme. These concepts add little to the NGO goals or are irrelevant to the needs they seek to address, making them only a rhetoric medium of legitimating activity (ibid.). In order to make them work in practice, NGOs in transitional settings, then, may re-interpret Western values to suit the local context, sometimes with a productive and desired outcome while at other times to the detriment of the civil society building plan.

In the mid 90s onwards there came the realisation that building civil society was not about pouring money into the country to set up certain types of NGOs based on and directed by Western ones (Wojnarowski and Jefferies 2000). Today NGOs in transition states are increasingly set up by local activists rather than by international or foreign NGOs, favouring the establishment of a more representative image and making them more 'contextualised', using Mercer's (2002) concept. From a knowledge perspective, the optimal result would come from the pooling of local and internationally based knowledge with continual adaptation and re-negotiation between the West and East to create a new culture (a hybrid approach) (Camiah and Hollinshead 2003). As NGO and civil society discussions develop, a new direction of Western assistance is possibly emerging - one allowing for a more sustainable and representative indigenous NGOs, more equality in the process of planning, a less asymmetrical gain in terms of learning from the organisational links, recognising common values in addition to the developmental outcome for the less developed country.

\section{The case study}

Following this discussion on the voluntary sector and its place in East-West engagement, a case study on a Bulgarian NGO, initially conducted in 2004, is presented below in order to examine the questions raised on transition (Bogdanova 2004, 2005). The case provides grounds for the emergence of a theoretical construct, organizational mentoring, discussed further on. (Full details are given in Appendix).

\section{Organizational mentoring framework for the voluntary sector}

The discussion on mentoring is found in the field of career guidance, workplace education and counselling, usually taking place within the organisation and to the organisation's benefit. Various highlights of how mentoring is looked upon and understood converge into a shared perception - mentoring involves experts (or individuals with advanced experience) passing knowledge to the usually younger protégés, a supporting exchange within a highly personal bond of mutual satisfaction, to the outcome of psychological development (Daloz 1986; Kram 1983; Aryee, Chay 1994).

In Clutterbuck's framework mentoring is bestowed with a multi-dimensional enhancement of a trust-based relationship based on various roles of the mentor as a coach, networker, counsellor, facilitator and guardian, each relating to the self- or career- promotion in a directive or non-directive manner (op. cit. 1998). Kram (1983) introduces the notion of mentoring phases and 
how the relationship between the mentor and protégé transforms with time on the basis of their needs and organisational circumstances. It shows that the relationship transcends the practical managerial approach focusing on the use of mentoring, as the deeper psychological effects signal the need for a more holistic approach to this type of bond, linking it to sociology and psychology disciplines. Gibb (2003) constructs a framework of three mentoring themes against which one asks the critical questions to conceptualise the mentoring relationship - relationship managerialism versus holistic approach, the mentoring functions, and the question of availability of mentoring. Kram's (1983) work introduces the time aspect into the relationship, giving it a dynamic dimension by focusing on its quality to transform over time.

The literature on mentoring begins to take shape as a lens through which one can look at the East-West partnership between the two NGOs in terms of assisted organizational transformation. The first theme in Gibb (2003) asks the question how to mentor, which relates to the process and content of change, very much like styles of mentoring. The first type is in favour of mapping and formalising activities to the effect of meeting the organisational aims under the managerial guidance, while the second favours the holistic approach to a complex environment considering that everything is interconnected and seeking to understand the links.

This is an important point - it addresses the transition/ transformation dichotomy introduced at the start of the paper, by allowing for both discourses as embodied by two distinct styles of mentoring, one more linear and the other, more innovative. Returning to the findings in the case study, managerial-type guidance is visible in the relationship. The workshops and advice for BSPB employees are aimed at developing their management skills to meet the goals of the BirdLife network. On the other hand, RSPB has an 'our goals, their way' strategy in managing the relationship with their Bulgarian partner, as “. . RSPB does not attempt to change a partner's culture but to work within it using its potential...". This can be argued as being the holistic approach to the complexity of the environment that Gibb talks about.

Gibb's second theme is on the purposes of mentoring, addressing the divide between liberal values in favour of "promoting humanistic ideals through improved psychological development", and conservative values, which ascribe a "continuity of the status quo [in] replicating behaviour patters" to the mentoring function (ibid.: 46). In terms of organizational change, this relates to the question of the motivations behind and direction of change. Looking at the mentoring RSPB, there is evidence in the findings that there is a case of legacy which is being passed onto the protégé, for example with the collective strategy development. There is also an awareness from both mentor and mentee that he context in which the BSPB operates is not that of RSPB. This calls for reinterpretation of the existing knowledge the RSPB offer. There is certain defensiveness by RSPB regarding the efforts they make to pass on their knowledge to the protégés, which may be a form of self-reassurance that the transfer of experience is beneficial and will yield the desired outcome. How much is that a matter of serving the generative needs for the RSPB rather than facing the reality of outcome uncertainty in this transfer remains unanswered.

Finally Gibb (2003) attends to the issues of who should mentor in terms of mentor availability and matching the two sides, touching on practicality and mentoring styles. This translates into the agency of change and raises the question of who is being left out through mentoring in the process of building the civil society base of Bulgaria. As an example, there is external support for the environmental protection activities in the country other than the assistance of RSPB like the federation of environmental NGOs, Green Balkans, which get the support of WWF. There are tensions between indigenous organizations despite their working towards the same goal in the same environment, supported by different external partners, which makes this hardly an example of successful building the civil society with the help of external assistance.

It seems to me that organizational change can be understood in the context of the mentoring model proposed below (Harrow, Bogdanova 2007). Its components can be aligned with the three directions of developing the mentoring model.

\section{Theory-building: directions for further development of a mentoring model}

In this diagrammatic expression, the contextual projection corresponds to the (1) direction of change in terms of what transition means on an institutional, cultural, and individual (to the organization) experience level. The knowledge projection, referring to the transfer of knowledge between mentor and recipient can be related to (2) content and process of change, i.e. what is transferred, how much and by what means. Lastly, the actor projection is regarded here as (3) agents of change, the organizations engaging in the exchange and ultimately driving the transition process. 


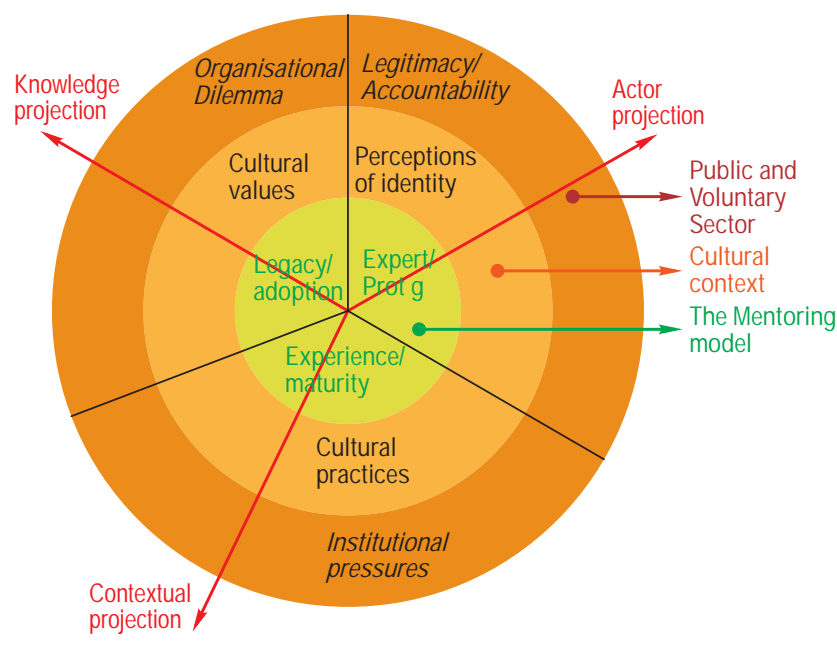

Knowledge, Actor and Contextual Projection

Turning to the 'phases' model introduced by Kram (1983), this approach to mentoring suggests that organisational mentoring as a conceptual construct has the potential to aid the transition discourse by providing a crucial element - that of measurability. In the initiation stage of the relationship the mentee is likely to seek relationships that provide opportunities for resolving the dilemmas posed in early career years, something that can be observed in the case study between the BSPB and RSPB via their membership in BirdLife. According to the findings, the RSPB assist the younger organisation in resolving their management and planning dilemmas but do not advise them on how to implement the plans in relation to the cultural and institutional context. This raises the question of whether the experienced RSPB is only contributing to the resolving of dilemmas or, by keeping a hands-off rule to allow for initiative and cultural contextualisation, is inevitably contributing to their proliferation.

When the mentee feels more autonomous, s/he will no longer look to the mentor for the same kind of support. The RSPB and BSPB show to be aware of and aligned in their progressing relationship and there is an apparent movement toward greater sustainability of the Bulgarian NGO (financial dependence reduced to 30\% and subsiding assistance on planning and managerial skills). However, when applied to the case of external NGOs mentoring other NGOs in their indigenous environment, the phase aspect of mentoring is perhaps in need of modification to account for the autonomy existing throughout the relationship. It can be argued that because the two NGOs are independent actors in their own locality, the mentee preserves a certain degree of autonomy of action, making the relationship more peer-like from the very beginning rather than reaching that state in the redefinition stage of Kram's model.
Finally, the external mentoring of NGOs in transitional environments is bound to reach a point of exit when the maturity of the organisation and self-sustainability reaches adequacy. In Kram's framework, this translates into exhausting the return for the participants in the relationship, leading to a discussion on the return for the external NGO and to what extent the mentoring logic based on individual needs be applied to the condition of organisational needs. Taking the exhaustion point as that of reaching maturity, we revert back to the findings and the difficulty in distinguishing a maturity that comes with time from maturity perceived as part of cultural makeup. If the weaknesses of BSPB are a matter of cultural difference (from the RSPB respondent interview) whereas maturity is a matter of time and gaining experience, does maturing come with time and proper guidance or is cultural "hindrance" stronger than time and the efforts of the mentor and mentee? What does that indicate for the future of transitional economies mentored from the outside? These questions remain outstanding for the whole field of transition analysis and cannot be answered at this point, with or without a mentoring construct.

\section{Discussion and conclusion}

Looking back at the literature and case study findings with organizational mentoring as a context, is it more useful to talk about "transition" or about "transformation" in Eastern European societies? It could be argued to be a matter of practicality, clarity of goals and measurability of progress and perhaps a matter of choosing to stay real over choosing to be idealistic. As the case study implies, "getting things done" is a more important, or perhaps a more realistic task to the NGO in comparison to changing the perception of society about the importance of voluntary sector organizations as a whole. If transition offers a linear process towards a definable point with a path to arriving there and experience in the consequences of achieving that goal, it sounds like a more rational choice in comparison to the more illusive transformation path. In this sense, transition can be over whereas transformation never is.

As the case implies, perhaps the voluntary sector in particular will know when transition is over if the society in transition is modelling its organizational development on that of another society, which has gone through a similar process. Measuring success in the sector is grounded in knowing what its purpose, its outputs and outcomes are - to create an environment of choice in belonging and a voice in decision-making for the various groups that make up society. Learn- 
ing about defining and measuring these indicators is possible through a mentoring relationship described. Measuring success nevertheless is feasible only as long as the desire to characterize the resulting culturally laden "civil society" is kept at a safe distance from the pragmatist work of NGOs, regardless of whether that divide is a West-East or inter-East one.

This paper has argued that organizational mentoring is a useful construct here in terms of measuring success when there are shared values and goals between organizations. In a macro-transition context, the policymaking field, increasing the chances of successful lesson-drawing across countries is based on criteria which can be related to the elements of mentoring. For example, Rose emphasises the importance of contingencies between the two sides in the context of crossnational lessons on public policy - the learning and the knowledgeable society. As in management discourse, success is likely when there is a clearly defined objective, a single goal, a simple design, there is flexibility in relating the elements of programme being applied, it is based on tested knowledge, and there is commitment from leaders (ibid.: 118). It is important to note that the flexibility element is perhaps the key (and greatest challenge) to overcoming the cultural differences that may challenge knowledge transfer in the case of any organizational mentoring pair (the question of redefining to fit the context). In effect, the degree of flexibility determines whether transition or transformation is the more explicit approach to mentoring.

A perspective of a mentoring organization rather than a classical assistance model may be a better means of understanding the interorganizational relations in the voluntary sector. With further development, this model lends itself to application in other types of organizations as well in terms of transition settings. It is argued that mentoring is a better structure for needed development, at the least from the point of view of the mentored organization - it is more self-driven for the indigenous organizations and based on mutual exchange rather than a one-way flow of technical guidance (from the West).

However, it is recognised that proposing the existence of a mentoring relationship may offer new difficulties as well as advantages. How does the mentor's assistance reflect on the values and practices of the mentee? For example, does the mentor's legacy of knowledge and experience answer the mentee's need for support in fulfilling its mission? Specifically, the current need for Bulgaria to quickly adapt to the EU as a new member may imply that having a UK-based organization as mentor may not be the most appropriate choice. Much of the voluntary sector in the UK is not very comfortable with the procedures for applying for EU funding and has also been criticised by the Commission for "discrimination of foreign charities" (EUROPA 2006).

Other difficulties relate to the point of exit from the mentoring relationship - do the mentors leave when there is no more generative return? Is that sooner or later than when the mentee is ready to exit the mentoring relationship? Furthermore, regardless of the motivation behind the mentor's support, mentoring in the voluntary sector is a question of developing multiple civil societies in which the needs and interests of different groups are not necessarily based on complementary goals. Ultimately, who has the responsibility to build civil society in transitional countries, especially those undergoing European Union accession? Debates regarding the end of transition are still open. For example, the current democratic backsliding in the Central European transition countries after an exemplary period of change (Freedom House 2007) may actually be a sign of the end of a transition rather than evidence of regression, that is, if a crisis in democracy is said to characterise the developed world overall.

Further research is needed on assistance to different parts of the voluntary sector in transitional environments, to assess the balance of the types of support multiple civil societies are receiving and to what relative effect. The mentoring model offers a different way of looking into the negotiation of a compounded culture and research needs to be carried out in other sector settings in transitional contexts to explore this further. According to the mentoring construct in the case, as early relationships transform into more balanced exchanges, there is a move away from the transferring of models to developing a "new type" of civil society, as a mix between the mentor's assistance and the mentee's experience and culture. In this sense, transition must take place before transformation is possible. Overall, it is possible that this developmental model on organizational mentoring is helpful in understanding (and describing) the shift in focus from transition to transformation. 


\section{References}

Alas, R. and Tuulik, K. 2007. Cultural practices and values at the societal level in Estonia in comparison with neighbouring countries, Journal of Business Economics and Management 8 (1): 39-44.

Alexandrov, H. 2007. Rural Development Programs, in Proceedings of the DIOSCURI Final Conference, Institute for Human Sciences, Vienna, April 20-22, 2007.

Alvesson, M. 1991. Organisational symbolism and ideology, Journal of Management Studies 28(3): 207-25.

Andreeva, D.; Dushkova, I.; Petkova, D.; Mihailov, D. 2005. Civil society without the citizens: Measuring the Bulgarian civil society index (2003-2005), Balkan Assist publication. Available from Internet: $<$ http://www.balkanassist.bg/en/ProjectDetails.jsp?prjID $=18>$.

Aryee, S. and chay, Y. 1994. An examination of the impact of career-oriented mentoring on work commitment attitudes and career satisfaction among professional and managerial employees, British Journal of Management 5: 241-249.

Avramov, R. 2007. Think tanks in the world of applied economics: a comparative view across Eastern Europe, in Proceedings of the DIOSCURI Final Conference, Institute for Human Sciences, Vienna, April 20-22, 2007.

Bebbington, A. and Farrington, J. 1993. Governments, NGOs and agricultural development: perspectives on changing inter-organisational relationships, Journal of Development Studies 29(2): 199-219.

Bogdanova, M. 2004. Implementing organisational values and goals: a reality of $N G O s$, University of Warwick Business School, unpublished M. A. dissertation.

Bogdanova, M. 2005. NGO mentoring and development in a transition economy, in Voluntary Sector Studies Network Conference, November 30, 2005, LSE Centre for Civil Society.

Brandsen, T.; Donk, W. and Putters, K. 2005. Griffins or chameleons? Hybridity as a permanent and inevitable characteristic of the third sector, International Journal of Public Administration 28: 749-765.

Burawoy, M. 2001. Transition without transformation: Russia's involutionary road to capitalism, East European Politics and Societies 15(2): 269-290.

Camiah, N. and Hollinshead, G. 2003. Assessing the potential for effective cross-cultural working between "new" Russian managers and western expatriates, Journal of World Business 38: 245-261.

Cassar, V. and Bezzina, C. 2005. People must change before institutions can: a model addressing the challenge from administering to managing the Maltese public service, Public Administration and Development 25: 205-215.

Chavdarova, T. 2007. The small entrepreneur: culture and economic action (the case of Sofia and Skopje), Centre for Advanced Study Sofia in CAS. Working Papers 1: 3-33.

Clutterbuck, D. 1998. Learning alliances: tapping into talent, London: Institute of Personnel Development.
Crotty, J. 2003. Managing civil society: democratisation and the environmental movement in a Russian region, Communist and Post-Communist Studies 36(4): 489-508.

Daloz, L. 1986. Effective teaching and mentoring. San Francisco, CA: Jossey-Bass Inc.

Deal, T. E. and Kennedy, A. A. 1982. Corporate cultures. Reading, MA: Addison-Wesley.

Edwards, M. and Hulme, D. 1996. Too close for comfort? The impact of official aid on nongovernmental organizations, World Development 24(6): 961-973.

Europa. 2006. Commission requests the United Kingdom to end discrimination of foreign charities, Press release, Rapid, Brussels, July 10, 2006. Available from Internet: <http://europa.eu/rapid $>$.

Freedomhouse. 2007. Nations in Transit 2007: Governance crisis in Central Europe amid intensifying repression in Russia and CIS, Press release, Budapest, Hungary, June 14, 2007. Available from Internet: $<$ http://www.freedomhouse. org $>$.

Gibb, S. 2003. What do we talk about when we talk about mentoring? Blooms and thorns, British Journal of Guidance \& Counselling 31(1): 39-49.

Harrow, J. and Bogdanova, M. (unpublished). NGO mentoring in a transition economy: a fledgling organisation in Bulgaria, VOLUNTAS, under review

Kabakchieva, P. 2006. Petya Kabakchieva on DIOSCURI and the twin sides of cultural encounters, Centre for Advanced Study Sofia, Newsletter 1: 8-9.

Kram, K. 1983. Phases of the mentor relationship, Academy of Management Journal 26(4): 608-625.

Kram, K. 1985. Mentoring at work: developmental relationships in organizational life, Glenview, IL: Scott, Foresman.

Lavigne, M. 1999. The economics of transition: from social economy to market economy. London: Macmillan.

Maren, M. 1997. The road to hell: the ravaging effects of foreign aid and international charity. New York: The Free Press.

Mercer, C. 2002. NGOs, civil society and democritization: a critical review of the literature, Progress in Development Studies 2(1): 5-22.

Micklethwait, J. and Wooldridge, A. 2000. A future perfect: the challenge and hidden promise of globalization. Heinemann, London.

Narozhna, T. 2004. Foreign aid for a post-euphoric Eastern Europe: the limitation of western assistance in developing civil society, Journal of International Relations and Development 7: 243-266.

Pettigrew, A. M. 1990. Is corporate culture manageable? in Wilson, D. and Rosenfeld, R. (eds.). Managing Organisations: 267-272.

Pinnock, K. 2002. The impact of the NGO sector and Roman/Gypsy organisations on Bulgarian social policy-making 1989-1997, Journal of Social Policy 31(2): 229-250. 
Popov, J. 2007. The attack of the Strandja bloggers, in Dnevnik, August 5, 2007. Available from Internet: <http:// www.dnevnik.bg/>.

Townsend, J. G.; Porter, G. and Mawdsley, E. 2004. Creating spaces of resistance: development NGOs and their clients in Ghana, India and Mexico, Antipode 36(5): 871-889.

Tvaronavičienè, M. 2004. Theoretical framework for restructing of transition countries, Journal of Business Economics and Management 5(2): 41.

Uphoff, N. 1993. Grassroots organizations and NGOs in rural development: opportunities with diminishing states and expanding markets, World Development 21(4): 515-530.
Vivian, J. 1994. NGO and sustainable development in Zimbabwe: no magic bullets, Development and Change 25: 167-193.

Wojnarowski, J. and Jefferies, N. 2000. Partners without partnership, Central Europe Review, 2(March 11). Available from Internet: <http://www.ce-review.org/00/11/wojnarowski11.html>. 


\section{Appendix. Case Study of RSPB and BSPB}

\section{$R S P B$ and BSPB}

The RSPB is over 100 years old and started out as an action against plumage trade. Today it is the largest conservation organization in Europe with $£ 50$ million income per year, over 1 million members, 13,000 volunteers, 1440 employees, and 182 nature reserves. It works on policy-influence, habitat conservation, research and international programmes. The RSPB is a sector titan in the UK and has the support and recognition of a substantial part of the country; it is internationally recognised and arguably, desired as a partner by the voluntary sector anywhere in the world.

The BSPB is established in 1988 with an already wider goal - bird protection and biodiversity conservation, without the historical process of gradual development from a single task to an ambitious mission. It is comparatively smaller with 22 employees and 800 members, 5 regional offices and 2 conservation centres. It is still Bulgaria's largest and the only one managing protected areas. Activities are the same as its partner's - conservation, advocacy, education and international involvement. Despite the respect from institutional actors it has gained, the $B S P B$ is not a name recognised and respected by the public majority. Speaking out 'for the protection of birds' makes Bulgarians snigger, something which RSPB is far less likely to have experienced.

What links the two is the shared mission and values around the conservation of birds and nature. The legitimating body for recognising this mission as a global goal is the BirdLife International conservation partnership, under the guidance of which the RSPB became a partnering organisation for sustainable development of the younger $B S P B$ in 1994. The RSPB finances some of the activities and provides its time for sitting in and setting strategy together with their partners. The assistance also involves workshops for BSPB employees aiming to developing diverse skill such as financial management, personnel management, and good governance. Both organisations are partners in the same overreaching organisation, invited separately based on their achievements, although one is clearly more experienced and has greater capacity to carry out its goals. Responses from both sides point to a collaborative partnership and mutual respect as well as shared set of values and standards. The strategy which the RSPB has in assisting their Bulgarian partner is based on identifying targets and setting objectives together, not the means, as that is left to them [BSPB] and their unique organizational culture. 